\title{
Multidetector Computed Tomography for Assessing a Pulmonary Artery Sling in a Pediatric Patient
}

\author{
Xihong Hu - Guoying Huang · Mier Pa
}

Published online: 23 May 2008

(C) Springer Science+Business Media, LLC 2008

\section{Erratum to: Pediatr Cardiol}

\section{DOI 10.1007/s00246-007-9193-9}

In the online and printed version of this article two co-authors were mistakenly omitted (Guoying Huang and Mier Pa).
The complete and correct list of authors appears above and below:

Xihong $\mathrm{Hu} \cdot$ Guoying Huang · Mier Pa

The online version of the original article can be found under doi:10.1007/s00246-007-9193-9.

X. Hu $(\bowtie) \cdot$ G. Huang $\cdot$ M. Pa

Heart Centre, Children's Hospital, Fudan University,

Xuhui District, Shanghai 200032, China

e-mail: huxihong@gmail.com 